\title{
An Analysis of Theories Related to Experiential Learning for Practical Ethics in Science and Technology
}

\author{
Suma Parahakaran ${ }^{1,2}$ \\ ${ }^{1}$ Sathya Sai Academy, Malaysia \\ ${ }^{2}$ Singapore Academy of Educational Excellence (SAEE), Singapore
}

Copyright $\mathrm{O} 2017$ by authors, all rights reserved. Authors agree that this article remains permanently open access under the terms of the Creative Commons Attribution License 4.0 International License

\begin{abstract}
Learners in higher education are self -driven to attain goals and objectives of what is required by the Universities for career prospects in the fields of Sciences and Technology. This paper analyses theories of experiential learning which will contribute to implementation of Ethical behaviors in science and technology towards citizenship learning. This paper will focus on the theoretical aspects of the conceptions of learning, cultural implications of learning, how different types of knowledge contributes to learning and analyses why such knowledge and learning is insufficient to meet long term sustenance in life. Educational aims for sustenance of life through theories and practice have been discussed in ancient texts and education requires the reintegration of Ethics in all disciplines, particularly in Science and Technology. Education for higher order thinking emphasizes on creating discriminative skills, critical thinking, implementing knowledge as reflective practitioners and for the progress of society. The review and analysis of Experiential Learning theories [1, 2, 3, 4] and its contribution to practical ethics is discussed in this paper. The emphasis on knowledge and skills are explained by theorists and this paper discusses how the theories can be implemented in critical pedagogy for practical ethics related to the fields of Science and Technology at the tertiary level.
\end{abstract}

Keywords Practical Ethics, Science and Technology, Experiential Learning, Culture and Learning Theories

\section{Introduction}

The following sections explore different conceptions of learning. The crisis of today's issues with Science and Technology in society lies with exclusion of ethics in experiential learning and application of theories relevant to sustenance of life. Although researchers work with scientific and logical conceptions of knowledge for practical implementation, it has not attempted to research on conceptions of learning, cultural implications of learning, the categories of knowledge that deal with the sustenance of life and how to deal with the integration of ethical aspects with the outcomes of knowledge. The aim of the paper is not to analyze strengths and weaknesses of the theoretical perspectives but analyzed the conceptions of learning by few researchers and the sources of knowledge related to experiential learning.

\subsection{Ethics, Science and Technology}

The aim of integrating the research in this paper on the "sources of knowledge, ethics and conceptions of learning" is to reflect on the larger purpose of their applications for long term sustenance of knowledge for lifelong learning.

Knowledge as according to Kolb [5] "is a transformation process being continuously created and recreated, not an independent entity to be acquired or recreated" [6, p.38]. William James in 1980 as cited by Kolb [5], expounds on the role of consciousness and marveled at the continuity of it as one woke up from sleep. He marveled at the capability of human beings being able to wake up with the same thoughts, feelings, memories and sense of who the person is. This continuity of learning through life's experiences is also described from works of Dewey by Kolb [5]. According to Kolb [5] the role of the consciousness and subjective experiences in learning is important and all the four; experience, perception, cognition and behavior will contribute a holistic approach to the conception of learning.

Knowledge is therefore an outcome of a process of learning which is related to sense experiences. The feeling of continuity of such learning and understanding defines somewhat the role of consciousness. However, without memory, the sense of continuity will cease to persist and it is memory that connects learning from one experience to another. This means that consciousness has a bigger role to play; to hold memory, experiences derived from the senses and the continuity of body experience. This consciousness according to Baba [4], allows conscience to enter the body [4, p.258]. The Vice Chancellor of the Higher Institute of 
Learning introduced three terms which is related to learning. They are conscious, conscience and consciousness. Learning can be defined as that which is known through the senses (conscious), without the context of time and place (consciousness) and one's personal discriminatory faculties which includes critical reflection (conscience).

There is evidence of such learning from the works of Purdie and Hattie [5] on a multicultural sample consisting of Australian and Japanese students. They identified nine categories of the conceptions of learning; growth of knowledge, accumulation of information through memory and being able to produce it; applying the information to achieve goals, understanding, perceiving things from various other perspectives, personal fulfilment, a duty, process that is not bound by time or context, and progressing in social competencies. The last two categories of learning arise from a sense of being beyond personal, expanding to integrate aspects of the social world. Studies from Tynjala [6] identified identical categories; learning which is developmental and that transcends time and context, learning as an interactive process between people. Kolb and Fry [7, p. 52] defined the three theoretical implications of experiential learning as; "environment to be broadly defined as formal educational approaches, observable and controllable factors can be related to individual differences in behavioural learning styles, person- environment interaction must be related in the context of growth and developmental goals for the learner" p. 52. From Kolb's model related to the process of experiential learning (p.25) and his explanation of the need to understand experiential learning from a more holistic perspective, it is evident that experiential learning is a continuous process. It encompasses perception, cognition, experience and behavior. To summarise, consciousness encompasses perception, cognition, experience, behaviours, and acts related to the conscience. Research in Science and Technology has failed to explore the conceptions of learning related to critical learning for both individual and fundamental discrimination, how one critically use their learning for their own benefit and for the sustenance of the society.

\subsection{Science and Wisdom: The Origins}

According to Louth [8] earlier in the monastic learning there were two kinds of life; active and contemplative life (bios praktikos and bios theoretikos) which was known even during the time of Aristotle and known to both Aristotle and Plato. In Arsitotle's view worldly activity was divided into world of business and commerce, farming and manufacture, everyday life happenings, and the world of thought. The active life was meant to be concerned with the moral and political issues of worldly life as compared to the world of thought. Hence the word theoria originates from the word "to look" or "to see" and in Greek term, a seeking of the intellectual. Contemplation therefore symbolized knowledge, knowledge of reality, in contrast to knowing how, and how to be practical. The essence of this paper therefore focuses on these two worlds as expressed by Louth [8];

"To this contrast between the active life and contemplation there corresponds a distinction in our understanding of what it is to be human between reason conceived as puzzling things out, solving problems, calculating and making decisions - referred to by the Greek words phronesis and dianoia, or in Latin by ratio - and reason conceived as receptive of truth, beholding, looking - referred to by the Greek words theoria or sophia (wisdom) or nous (intellect), or in Latin intellectus".

Aristotle expressed differences between practice and reflection as scientia; which defines the kind of knowledge by ratio and sapienta, wisdom for the kind of knowledge received by intellectus. Human knowledge as stated by Louth, operates at two levels, one is leading a life of practice and another level relating to beholding, contemplating and knowing reality [5, p.66-67].

\subsection{Knowledge and Learning}

Kolb [5] stated that to learn involves comprehension of nature and forms of human knowledge. From his overview of research from work of psychologists, Kolb stated that common sense can only be understood if one looks at it from the perspective of refined knowledge while refined knowledge can only be based on common sense because of the limitations of highly refined knowledge and learning process range from social to personal knowledge. This also includes cognitive and socio emotional perspectives [7].

Kolb [5] stated examples of learning ranging from scientific research and discovery to something as basic as the child's discovery that a ball bounces. The knowledge that is obtained from advanced research is based on previous experiences accumulated from many years of human experiences which he termed as objective experiences and the second example that is illustrated about the child's understanding that the ball bounces is a subjective experience.

Knowledge is an outcome of both objective and subjective experience which defines learning as a continuous process. Kolb [5], referring to Piaget's work in 1965, explained how knowledge is acquired, increased, organized or reorganized (p.651). Piaget's writings on inquiry into the nature of gaining knowledge indicated that knowledge either comes from the object or it is completely constructed by the subject or with more interactions between the subject and the object. The other perspective for the sources of knowledge was defined at the 2000 world conference in India. Baba [4] (2000), the Vice Chancellor of the Institute of Higher Learning, India stated that there are four kinds of knowledge. They are; bookish knowledge; general knowledge; 
discriminatory knowledge and fundamental knowledge. These different kinds of knowledge thus organized are the outcomes of different kinds of learning. The knowledge obtained from previous experiences of several cultural experiences is termed as superficial knowledge, which is bookish knowledge while knowledge that transcends time and experience is general knowledge. The third is discriminatory knowledge which are of two types. They are, as Baba [4] stated, individual and discriminatory knowledge. The first kind of discriminatory knowledge refers to knowledge gained for selfish purposes which is individual knowledge and the second is fundamental knowledge which is knowledge related to the welfare of all beings. Using knowledge for creating new systems, for example do not take into accounts of philosophical challenges of computing ethics as reflected by Macer 2004 [9]. The authorities from various fields of Science and Technology do not take into account the outcomes of knowledge and its applications from an ethical perspective. What were the intentions behind knowing what is new and how to use the new information for the welfare of the society? These questions invoke an individual scholar to choose his or her actions of power, politics and ethics but do not contribute to sustenance of prosperity or success in the long run. The crisis of today's education lacks understanding the nature of being human as we do not link the relationship between reasoning for implications of knowledge known through learning of procedural facts for solving problems (Science) and reason conceived as Louth states for wisdom or intellect. Knowledge and its application have cultural implications and how knowledge is used. Macer[9] defined ethics as follows;

\begin{abstract}
"The word "ethics" is closely related to love. Love is the desire to do good and the need to avoid doing harm. It includes love of others as oneself, the respecting of autonomy. It also includes the idea of justice, loving others and sharing what we have - distributive justice" Macer, [9].
\end{abstract}

The required changes related to ethical implications of learning in Science and Technology lies on the shoulders of authorities in Higher education and how they encourage student participation in the realities of life for life- long learning. There are various conceptions for the word "learning" and from the academic research conducted the findings are provided below.

The focus in this paper is to provide an overview of the following:

- Conceptions of learning and knowledge (How learning occurs and what forms of knowledge)

- Ethics, Science and Technology (Summary of nature of learning for knowledge and for wisdom).

\subsection{Conceptions of Learning}

The section below expounds only on few prominent researchers on the topic of learning. They, Saljo [1], Purdie,
Hattie and Douglas [10] and Purdie and Hattie [5] defined the conceptions of learning using samples from different parts of the world.

The questions explored on learning included; what learners meant by learning and how do learners establish their learning. Säljö [1] explored a sample of ninety Swedish teenagers and adults' whose ages ranged from 17-93, on their understanding of the concept of learning. This sample involved participants from different levels of formal academic learning. The results included various different conceptions of learning such as; (i) an increase in knowledge, (ii) memorizing, (iii) acquiring facts which is retained and used practically, (iv) knowing the meaning of what they learnt and finally (v) an interpretive process which was focused on understanding reality.

These conceptions of understanding were categorized as surface level (ii, iii) and deep level processing (iv, v). Saljo's findings from his work similarly revealed that learners make sense or find meaning which involves parts of subject matter, relating sometimes to each other and to real situations. Nickerson [11, pp. 217-234] as cited in Entwistle \& Nisbet [12] stated that learning connects facts and integrates new knowledge into a "cohesive whole". Understanding, he asserted is sense oriented and this changes over time as both concepts and theories are time related. The concept of learning made aware through the senses changes over time and learning moves from a surface approach to deep approach. Other researchers who researched on the conceptions of learning defining the deep and surface learning approaches were Entwistle \& Ramsden [12] and Marton [13]. Perkins and Blythe [14] explained the concept of learning as a process well enough to comprehend, analyse and apply the concepts. Richardson [15] summarized the concept of learning by stating that learning depended on the content, context of learning and what the tasks demanded. It can be summarized that learning for knowledge not only changes with time and requires application of learning according to the context in which learning should take place.

Purdie, Hattie and Douglas [14] in Purdie and Hattie [5] explored the conception of learning using a sample from Japan and Australia. They identified nine categories of the conception of learning. They were; Knowing more information (b) memorizing and able to produce the same information (c) applying the information (d) understanding (e) looking at different perspectives using the information (f) personal fulfilment $(\mathrm{g})$ taking responsibility of one's work (h) a process regardless of time and context and (i) developing skills for dealing with society. These categories demonstrate that as time evolves the learners have themselves integrated the conceptions of learning for life which extends from individual to the society or learning of an interactive nature. When both Purdie and Hattie [5] researched using a multicultural sample and their findings reported the following six conceptions of learning; "(a) gaining information; (b) remembering, using, and understanding information; (c) a duty; (d) personal change; (e) a process not 
bound by time or place; and (f) social competence" (p.27). The last two conceptions were also identified by a study conducted by Tynjälä [6] where categories included learning as a (vi) process which is not predictable or avoidable and (vii) learning that occurs interactively. The last two categories were identical in Tynjala [6] and Purdie and Hattie's [6] study indicating that conceptions of learning include learning which is of a different nature such as those that transcends time or place and is inclusive of the social sphere.

\subsubsection{Importance of Reflection}

Brookefield [2] asserted theoretically on the importance of learning involving both action and reflection, wherein the curricula must not expound knowledge isolated from real learning but learning related to their conceptions of ideas, related skills and knowledge with "feelings in an immediate and relevant setting" [16, p.16]. He also asserted the significance of the opportunity to reflect on experience. Brookefield [2] emphasized the integration of both critical reflection and experience in higher learning.

\subsubsection{Kolb's Learning Theory}

The work by David Kolb [5] in 1984 defined learning as that which integrates learning and experience. Kolb gave significant importance to applying abstract learning into immediate practice so that it can be a "publicly shared reference point for testing the implications and validity of ideas created during the learning process" [6, p.21). Kolb's work resulted in a model that includes four stage learning cycle in which the learner can experience all the four phases; concrete experience; reflective observation, abstract conceptualization and active experimentation. In the concrete experience stage the individual is in direct experience with a new encounter or interprets existing experience. In the reflective experience stage the learner reflects on the new knowledge and is in a state of understanding whether the learning is right or wrong. This leads the learner to a new idea or a modification of a concept that already exists and modifies the new idea which is referred to as the abstract conceptualization. In the final stage the learner applies to the world which stimulates learning termed as active experimentation.

\subsection{Cultural Implications of Nature of Learning}

There are different ways students conceptualize what they learn depending on the cultures they come from. Results of Joy and Kolb's [17] study of cultures related to learning styles in many countries revealed that culture influences learning. Various cultures have their influences in learning (Socratic, Confucius, Islamic education and education in the Gurukula system in India) have impacts on how students conceptualize their learning. There are different views of learning styles within cultures (from heterogenous groups) and those cultures that have practiced collectivistic kind of approach (India, China, Japan, Malaysia, Thailand,
Cambodia, Africa etc). The cultures of these countries have different ways of learning compared to groups of people who originate from individualistic kind of learning (America, Australia, Europe etc). The homogenous cultures had to systematically learn through recitation of verses and reinforce learning of these verses in their memory in the Southeast Asian regions. Confucian and Socratic approaches can be adaptive depending on the contexts, Tweed\& Lehman [18]. Their argument was that Socratic approaches to learning tended to be more inductive, eliciting self- generating knowledge questioning learners' beliefs. Students from the Confucius kind of learning styles, in Tweed and Lehman's [18] opinion emphasized more on the commitment to learn, reforming behaviours and inculcating respectful learning so that they play a role in government tasks. In the Gurukula system in India, both Socratic and Confucius type of learning is emphasized in ancient Indian cultures. The practice using rigorous method such as in the Vedas (to know: knowledge) in Hindu culture is similar to the rote learning found in Confucian methods of learning. The knower or the preceptor (teacher) in both Confucian and Hindu cultures (Gurukula system) required students to learn virtue by imitating lives of virtue models (Parahakaran [19] and Tweed and Lehman [18].

The other similarities of Confucian cultures with that of the Hindu cultures include students respecting the source of wisdom (Master or teacher) by submitting to a master for acquiring wisdom. The learning of ethics for the prosperity of the country is found in ancient vedic culture, Parahakaran [19]. These two different approaches such as inductive and deductive kind of learning styles are explained in detail in the Vedas in ancient Hindu culture. The dominating culture in India (Hindu) included cooperative learning and inductive learning (through discipline for knowledge of the self). However, there is evidence that cultures that promote the Gurukula kind of learning also promotes a position of distance from the knower (Guru/ preceptor). This distance created through the process of learning does not support learner questioning authorities critically. Ethics is therefore a subject which has to be relooked collectively by experts in various disciplines for the good of many and prosperity of the country. The sources of knowledge on Ethics and how learning occurs are therefore interrelated matters and evolving depending on time, memory and context.

\section{Methods}

The theory development for learning in this research systematically organized the theoretical perspectives of a few researchers who researched on the conceptions of learning and who defined knowledge by defining types of knowledge related to experiential learning.

The nature of the knowledge, the source and how learning occurs with what forms of knowledge for sustenance of life are extracted from literature. The table below illustrates the relationship between learning, knowledge and how learning occurs. 
Table 1. Summary of theoretical perspectives by various researchers related to learning and forms of knowledge

\begin{tabular}{|c|c|c|c|}
\hline Year & Nature of learning for knowledge and for wisdom & $\begin{array}{l}\text { How learning occurs interactions and } \\
\text { what forms of knowledge? }\end{array}$ & Relevant researchers \\
\hline 1965 & $\begin{array}{l}\text { Knowledge comes from either the object or constructed by the } \\
\text { subject alone or multiple interactions from the subject and object }\end{array}$ & $\begin{array}{l}\text { Empiricism, apriorism, or diverse } \\
\text { interactionism }\end{array}$ & David Kolb \\
\hline \multirow{7}{*}{2000} & & & $\begin{array}{l}\text { Scientific } \\
\text { researchers }\end{array}$ \\
\hline & Bookish knowledge & $\begin{array}{l}\text { Learning gained from several years of } \\
\text { human experience, }\end{array}$ & Tynjälä [6] \\
\hline & General knowledge & leorning that tronscends time ond context & Brookfield [2] \\
\hline & & (2) & Brookfield [16] \\
\hline & Discriminatory knowledge & critical reflective knowledge & $\begin{array}{c}\text { Houle, [20], Borzak, } \\
\text { [21] Angela M. } \\
\text { Passarelli \& David }\end{array}$ \\
\hline & Practical knowledge & $\begin{array}{c}\text { Knowledge that is relevant with time and } \\
\text { context }\end{array}$ & A. Kolb [22] \\
\hline & & Here and now concrete experience & Kolb [5] \\
\hline \multirow{4}{*}{2000} & \multirow{4}{*}{$\begin{array}{c}\text { Consciousness } \\
\text { Conscience (learning to discriminate) }\end{array}$} & Sensory experiences, behaviours & $\begin{array}{l}\text { Jean Piaget [23] } \\
\text { Kolb [5] }\end{array}$ \\
\hline & & Perception, cognition & Kolb [5], Baba [4] \\
\hline & & Human values & Baba [4] \\
\hline & & Ethics & Plato, Aristotle \\
\hline
\end{tabular}

Application of Ethics to applied Sciences and Technology using experiential theory: It is apparent that learning for science and technology involves reflection on what has been learnt and applied and to re-conceptualise new knowledge pertinent to science and technology. However, reflection, contemplation and discrimination (critical thinking) of the application of the knowledge derived from application of science and technology is not specified in the curriculum in Higher Universities in 2000 until lately when the term sustainable education has been introduced in several learning spheres.

The use of knowledge gained by science and technology requires transparency of the intentions of agents to organize, classify, structure the use of the knowledge for the welfare of the society and not for individual gains. An example was the Tuskegee Syphilis study, in which the experiment involved 400 patients with Syphilis for forty years who were not informed of the purpose of the study. These patients were not given the common drug available from 1943 and had to look for other sources until in 1972 the press published the issue. The United National Congress then formed the National Commission for the Protection of Human Subjects of Biomedical and Behavioural Research which resulted in publishing a report on "Ethical Principles and Guidelines for the Protection of Human Subjects of Research" known as the Belmont Report [24].

Although science is value free, according to Lacey [25], a rational person ought to integrate the universal ethical value with the concerns of both financial and social conditions of the people before research is conducted. If a scientist were to be concerned about the community and the impact of the social conditions, then Science and Technology research and learning must incorporate ethics into their teaching. Olive [26] analysed that if issues related to the use of technology does not relate only to the application of technical objects but also relate to the intentions of the agents, then there is a need to evaluate the kind of knowledge that arises from the application of technology by such agents which includes both their intentional and non- intentional goals for creating such a technology.

Wynne [27] argued on the following;

"when scientific knowledge is deployed in the public domain, the social judgments of a relatively private research community which create closure and 'natural validation' around particular constructions of specialty scientific knowledge, need to be reopened (deconstructed) and renegotiated in a wider social circle, possibly one involving different epistemological commitments and expectations, and correspondingly different definitions of the boundaries between nature and culture, or (objective) determinism and (human) responsibility (p.126-127).

\section{Expected Results/ Conclusion/ Contribution}

The analysis of theories of experiential learning, conceptions of knowledge and the requirement for ethics to be integrated into learning of Science and Technology reveals that we are at a critical stage where learning has 
completely excluded a very important aspect of knowledge. Education for both Science and Technology requires that students understand how they learn, why they learn and for what purpose instead of theorizing for just application of the outcomes of Science and Technology.

More research needs to be done in the areas of critical reflection of the applications of Science and Technology for individual and social benefits. The agents propagating for research towards Science and Technology may need to think of integration of sustainability factors (findings related to context, time, future unknown risks, cost and degree of consequences) as the future of sustenance of society lies in their hands. The author is currently working on the factors that impact the implementation of new research findings with reference to ethical aspects. The above stated factors will be categorized so that each category will have specific questions for researchers and stakeholders of their respective faculties to run through. This exercise provides a guideline for Stakeholders to narrow down the timeline and reasons for implementing research findings. The resulting discussion will provide a structure for discussion and arriving at conclusions on the ethical aspects and sustainable solutions for communities. The probable solutions and their risks thus consolidated from new findings from research in Science and Technology are an important step to prevent destruction of lives and existing resources.

\section{REFERENCES}

[1] Säljö, R.Learning in the learner's perspective. 1: Some common sense conceptions (Report No.76), Institute of Education, University of G^teborg. ED173369; 1979.

[2] Brookfield, S.D. Using critical incidents to explore learners' assumptions. pp. 177-193. In J. Mezirow (Ed). Fostering critical reflection in adulthood. San Francisco: Jossey-Bass Publishers; 1990.

[3] Kolb, D.A. Experiential learning: experience as the source of learning and development. Englewood Cliffs, NJ: Prentice Hall;1984

[4] Baba, S.S. Sathya Sai Speaks. [Internet]. 33, 251-264. [Internet] Andhra Pradesh: Sathya Sai Books and Publications Trust; 2000. Available from

sssbpt.info/ssspeaks/volume33/sss33-16.pdf

[5] Purdie, N, Hattie, J. Assessing students' conceptions of learning. Australian Journal of Educational and Developmental Psychology, 2; 2002. 17-32.

[6] Tynjälä, P. Developing education students' conceptions of the learning process in different learning environments. Learning and Instruction; 7, 1997. 277-92.

[7] Kolb, D. A., \& Fry, R. E, Toward an applied theory of experiential learning. (1974). MIT Alfred P. Sloan School of Management.
[8] Louth ,A. Theology, contemplation and the university. [Internet] Studia theologica I, 2. (64-73); 2003 [cited 201610 December]. Available from: http://www.studiatheologica.cnet.ro/pdf/200302art2.pdf

[9] Macer, D. Philosophical challenges of computing ethics: UNESCO and Information Ethics.[Internet] MANUSYA: Journal of Humanities (Special Issue No.8 2004). Available from

http://www.manusya.journals.chula.ac.th/files/essay/Macer_p 22-36.pdf

[10] Purdie, N., Hattie, J., \& Douglas, G. (1996). Student conceptions of learning and their use of self-regulated learning strategies: A cross-cultural comparison. Journal of Educational Psychology. 88, 87-100.

[11] Nickerson, R. (1985). Understanding understanding. American Journal of Education; 93. 201-239.

[12] Entwistle, N \& Nisbet, J. 'The Nature and experience of academic understanding. [Internet]The Psychology of Education Review. 2013. 37(1), pp. 5-14. Available from: http://www.research.ed.ac.uk/portal/files/14426142/ENTWIS TLE_The_Nature_and_Experience_of_Academic_Understan ding.pdf. [Accessed 6th November 2016].

[13] Marton, F. and Säljö, R. On qualitative differences in learning. 1 - outcome and process. British Journal of Educational Psychology, 1976; 46: 4-11.

[14] Perkins, D. \& Blythe, T. Putting understanding up front. Educational Leadership. 1994; 51(5): 4-7

[15] Richardson, J. T. E. Students' approaches to learning and teachers' approaches to teaching in higher education. . Educational Psychology. 2005; 25 (6). 673-680. doi $10.1080 / 01443410500344720$

[16] Brookfield, S. D. Adult Learning, Adult Education and the Community Milton Keynes Open University Press. 1983.

[17] Joy, S., \& Kolb, D. A. Are there cultural differences in learning style? International Journal of Intercultural Relations; 2009. 33(1), 69-85. doi:10.1016/j.ijintrel.2008.11.002

[18] Tweed, Roger G.; Lehman, Darrin R. Learning Considered within a cultural context: Confucian and Socratic approaches. American Psychologist.v57 (2) 89-99. Feb 2002. ERIC Number: EJ646499.

[19] Parahakaran, S. The Gurukula System in Thailand [Advanced Diploma Thesis]. Institute of Sathya Sai; 2004

[20] Houle, C. Continuing Learning in the Professions. San Francisco: Jossey-Bass; 1980.

[21] Borzak, L. (ed.). Field Study. A source book for experiential learning. Beverley Hills: Sage Publications; 1981.

[22] Passarelli, A.M, Kolb, D.A. Using experiential learning theory to promote student learning and development in programs of education abroad. In M. Vande Berg, M. Page, \& K. Lou (Eds.), Sterling, VA: Stylus. Student Learning Abroad; 2012. P.137-161.

[23] Piaget, J. The construction of reality in the child. New York: Basic Books; 1954. 
[24] The National Commission for the Protection of Human Subjects of Biomedical and Behavioral Research. [Internet].The Belmont Report. April 18. 1979. Accessed from; http://or.org/pdf/BelmontReport.pdf

[25] Lacey, $H$.The ethics of science and technology. In Lorenzano, P., Rheinberger, H.-J., Ortiz, E. \& C. Galles (eds.). [Internet]History and philosophy of science and technology. Oxford: EOLSS Publishers Co. Ltd. 2010. 3. p.258-291. [10th December 2016]. Accessed from:

https://www.eolss.net/Sample-Chapters/C05/E6-89-16-00.pdf
[26] Olive, L. Introduction of ethics in science and technology. In: Lorenzano, P., Rheinberger, H.-J., Ortiz, E. and C. Galles (eds.), [Internet]History and philosophy of science and technology. Oxford: EOLSS Publishers Co. Ltd. 2010. 3. p. 211-256. [11 December 2016]. Accessed from: https://www.eolss.net/Sample-Chapters/C05/E6-89-15-00.pdf

[27] Wynne B. Uncertainty and environmental learning: reconceiving science and policy in the preventive paradigm. Global Environmental Change. 1992; 2(2):111-127. Available from, DOI: 10.1016/0959-3780(92)90017-2 